\title{
Influence of Age of the Firm as Moderating Effect on the Relationship Between Knowledge Management and Organizational Performance of State Owned Commercial Enterprises in Kenya
}

\author{
Milkah Kimonda Chebii ${ }^{1}$ Prof. Peter Lewa ${ }^{2} \quad$ Dr. James Karimi Ngari ${ }^{2}$ \\ 1.Research Scholar, Chandaria School of Business United States International University-Africa \\ 2.Chandaria School of Business United States International University-Africa, P.O. Box, 14634 - 00800 Nairobi, \\ Kenya
}

\begin{abstract}
Purpose of this study was to examine the moderating influence of age of the firm on the relationship between knowledge management and organizational performance based on return on equity and return on assets of state owned commercial enterprises in Kenya. This study was based on explanatory and descriptive research designs since they were more appropriate to test the hypotheses. The target population comprised of 275 members of top management team of 55 commercial state-owned enterprises in Kenya, as at $31^{\text {st }}$ October 2016. The study utilized simple random sampling to select a sample of 268 members of top management team in the 55 commercial state-owned enterprises. Response rate of $71 \%$ was obtained and analytical tests conducted were Pearson correlation coefficients, one way ANOVA, and Multiple linear regression. The correlation analysis between age of the firm (moderator) and organizational performance were: return on asset $(\mathrm{r}=0.02, \mathrm{p}=0.782)$ and return on equity $(r=0.102, p=0.164)$. The result for One-Way ANOVA was $F(14,172)=1.243, p=0.249$. The regression coefficient for interaction terms between age of the firm on performance and knowledge management were: knowledge acquisition, $\beta=0.111, \mathrm{t}(2.47), \mathrm{p}=0.015$; knowledge creation, $\beta=0.149, \mathrm{t}(4.03)$, $\mathrm{p}=0.000$; knowledge conversion, $\beta=-0.234$, $\mathrm{t}(-4.178), \mathrm{p}=0.000 ;$ knowledge sharing $\beta=-0.082, \mathrm{t}(-1.843), \mathrm{p}=$ 0.067 ; and knowledge storing $\beta=-0.051, \mathrm{t}(-1.156), \mathrm{p}=0.249$ respectively. This concludes age of the firm does not moderate the relationship between knowledge management and organizational performance based on return on assets, but age of the firm moderates the relationship between knowledge management and organizational performance based on return on equity of state owned commercial enterprises in Kenya.
\end{abstract}

Keywords: Age of the firm, Moderation, Return on Assets (ROA), Return on Equity (ROE)

DOI: $10.7176 / \mathrm{EJBM} / 11-3-02$

\section{Introduction}

The concept of Knowledge Management is the process of capturing, distributing, and effectively consuming that knowledge (Davenport, 1994). Knowledge management incorporates the discipline that encourages an integrated approach to identifying, capturing, assessing, retrieving, and sharing organization's information assets that include; databases, documents, policies, procedures, and workers' expertise and experience. This definition was further advanced by (King 2009) who viewed Knowledge Management as preparing, organizing and effectively controlling the systems, processes and people in the organization to safeguard knowledge related assets for improvement of organization's performance. Arguably the timing of appreciating KM as a discipline was propitious, as in the 1980s, the fervor for intellectual capital had generated interest for the recognition of information and knowledge as vital assets for any organization' survival. Letonja and Duh (2016) avers that methods of networking, transferring, sharing and converting knowledge are important in any firm performance due to their influence in innovations.

The World Bank (2001) asserts that industrial capital and land is no longer sufficient to create wealth in organizations, but that knowledge management has become a fundamental source of wealth creation. World Bank argues that countries are anxious to adapt systems and programmes that promote knowledge sharing but lack the tools and the experience to do so. No wonder when James Wolfensohn became the president of World Bank in 1995, he focused on the World Bank's role in spreading knowledge about development and encouraged the advancement of community of practices that brings together groups of individuals with common interest or knowledge to enhance the social nature of learning within organizations, which presents an alternative method to the outmoded vertical transmission of knowledge (Wenger, Etienne, Snyder \& William, 1999). The World Bank propositions are supported by Sher and Lee (2004) who argue that knowledge is gradually becoming the most important element of production beyond the traditional factors such as labour, land and capital.

However, the assumption that knowledge management is needed for knowledge accumulation to result in improved organizational performance possibly arises from the fact that scholars have opposing views about the impact of knowledge on organizational performance (Vera \& Crossan, 2003). It is expected that a specific category of knowledge, which is valuable, rare, inimitable and non-substitutable would lead to increased 
performance (Barney, 1995). On the other side of the discussion are authors who do not see a direct relationship between knowledge and performance arguing that organizations can always attain knowledge that may not lead to intelligent behaviour (Singh, Chan \& Mckeen, 2006).

Vera and Crossan (2003) suggested that the knowledge that is relevant may have a positive effect on organizational performance. This study underscores other researchers' contentment that knowledge is still viewed as a critical resource that can support organizations to sustain long term strategic advantage in competitive environments leading to improved organizational performance. On the other hand, Kalling (2003) argue that the empirical studies that focus on the links between knowledge management and performance often stop with proxies of performance. Though there are many proxies of performance, this study focus on Return on Equity (ROE) and Return on Assets (ROA).

In Kenya, the formation of state corporations dates back to post independence. In 1965 the Government, through sessional paper No. 10 of 1965 on African socialism and its application to planning in Kenya, resolved to establish state corporations with a view to: accelerating economic and social development, redress regional economic imbalances, increase Kenyan citizen's participation in the economy, promote indigenous entrepreneurship, and promote foreign investments through joint ventures. The policy envisaged that the nationalized operations would operate efficiently, cover costs and earn profits. This marked the beginning of government investments in manufacturing, agriculture and other sectors that came to be referred to as state corporations of Kenya (Government of Kenya, 2013).

Since their establishment, some of the state-owned commercial enterprises have failed to meet their financial goals and hence missed opportunities for development. Noteworthy is the fact that $21 \%$ (nearly a quarter) of the state owned commercial enterprises have been making losses (Government of Kenya, 2013). More, Carroll and Foss (2009) concluded that knowledge management plays a key role in enhancing organizational performance. Given this poor performance, there is need to identify the cause of such. This study examine the influence of knowledge management on organizational performance based on return on equity and return on assets of state owned commercial enterprises in Kenya. Further, the age of the firm will inform if the duration of operation has influence on how knowledge management influences organization performance.

The link between knowledge creation in management and organizational performance has been empirically explored, but rarely through assessing the state of knowledge management practice and comparing it with direct indicators of financial performance. Namely, some empirical studies focus only on specific aspect of knowledge management, not the whole knowledge management structure for instance, Lee, Lee, and Kang (2005) assessed the performance of an organization with respect to its knowledge. Harlow (2008) was assessing the level of tacit knowledge within organizations and its effect on organizational performance. There is a gap on caused by scarcity of literature on the adoption of knowledge creation and how such knowledge if available influences performance of organizations. Given that organizations are faced with insufficient literature guiding management of knowledge leading to dependency on short term solutions in implementing knowledge management (Ruchi, Salma \& Roma, 2016), there is need therefore to develop a theoretical and empirical framework in the Kenyan context.

At the work place, most organizations outline performance as the domain of finance department while knowledge management is situated in the department of Information Communication Technology (ICT), consequently deteriorating integrated initiatives to deliver the positive results needed to drive performance. Evidence of such failure is reflected in the increasing number of hired private consultants in the public sector to build capacity (yet such capacity may be located within another department), duplication of investment in information technology which has not improved the management of knowledge and the exploitation of the same to enhance performance in the state owned commercial enterprises (Chiganda, 2004). Thus this study responds to this gap and sought to investigate how knowledge management affects organizational performance of state owned commercial enterprises in Kenya. General objective of this study was to examine the moderating influence of age of the firm on the relationship between knowledge management and organizational performance based on return on equity and return on assets of state owned commercial enterprises in Kenya.

\section{Literature Review}

The study was anchored on four theories that underpin knowledge management variables and organizational performance. The first three theories can be categorized as the theories of behaviour. These are: (i) Social Capital Theory (SCT) by Bourdieu (1984); (ii) Theory of reasoned action (TRA) by Ajzen and Fishbein (1980); and (iii) Theory of planned behaviour (TPB) by Ajzen (1991), which are widely used models to discover the factors that influence behaviour. These models have therefore been examined in order to select the construct for this research. The study further discusses the Knowledge based view (KBV) and the Resource based view (RBV) theories (Conner \& Prahalad, 1996). The full paper discusses this in detail. The research was guided by the following conceptual framework 


\section{Independent Variables:}

\section{Dependent Variables:}

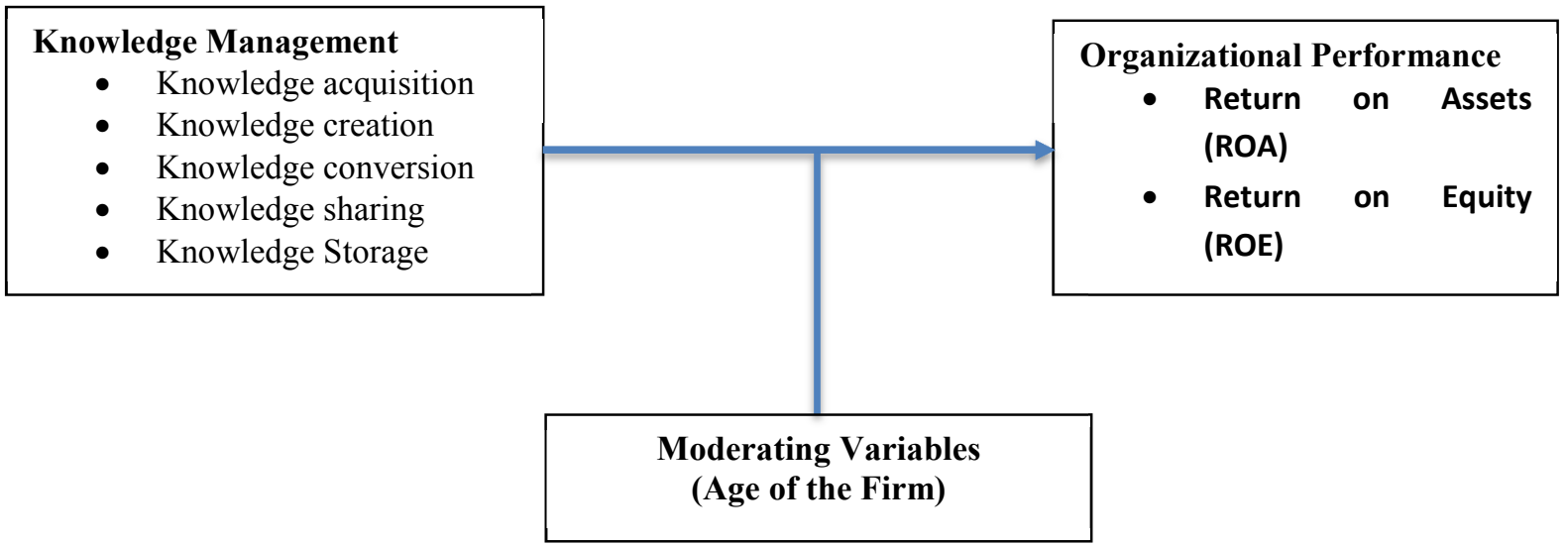

Figure 1: Conceptual framework

Studies on the effect of firm age on firm performance have generated mixed results ranging from those supporting a positive relationship among these variables to those opposing the same. Zaied, Hussein and Hassan (2012) explored the role of knowledge management in enhancing organizational performance in selected medium and large size organizations in Cairo, Egypt. The selected firms comprised of 10 public sector organizations, 10 private sector organizations and 10 non-governmental organizations. The study sought to examine factors that were considered in implementing knowledge management concepts to enhance organizational performance, further the study sought to provide an assessment tool that would help organizations to assess their knowledge management capabilities and identify any existing gaps in their knowledge management systems and suggest some possible ways to enhance organizational performance. Results of correlation analysis showed significant relationship between knowledge management elements and performance improvement measures such as decision-making of the firm.

Steven, Abby, Feng and Shisong (2017), undertook a study on 204 Chinese firms based in China to assess how firms' dynamic capabilities lead to competitive advantage and influence on firm performance. The authors theorized the dynamic capabilities into three discrete dimensions; sensing, integration and reconfiguration capability with results indicating that dynamic capabilities positively stimulate innovation that leads to improved firm performance. Data were collected from 204 firms randomly located in different cities in China and using PLS-SEM as the multivariate statistical method that allowed analysis of multiple variables, the results indicated that technological innovation is a critical mediating factor between dynamic capabilities and firm performance.

\section{Research Methodology}

This study used positivist research philosophy. This study was based on explanatory and descriptive research designs since they were more appropriate in enabling the researcher to test the hypotheses. The target population for this study comprised of 275 members of top management team of 55 commercial state-owned enterprises in Kenya, as at $31^{\text {st }}$ October 2016. The respondents in each of the organizations comprised of 5 members of top management that is; human resources manager, information technology manager, finance manager, administration manager/corporate communication and marketing/customer service relationships manager Sample size was obtained by Yamane (1967) sample size formula: total population 275, precision error 0.01.

$$
\begin{gathered}
n=N /\left\{1+N \varepsilon^{2}\right\} \\
n=275 /\left\{1+275(0.01)^{2}\right\}
\end{gathered}
$$

The study collected data from 268 members of top management team from the 55 commercial state-owned enterprises in Kenya.

The study utilized simple random sampling to select a sample of 268 members of top management team. Response rate of $71 \%$ was obtained and analytical tests conducted were Pearson correlation coefficients, One Way ANOVA, and Multiple linear regression.

\section{Results and Findings}

The study sought to determine normality of the independent variables. Based on results on Shapiro-Wilk, the knowledge creation variable was statistically significant $(\mathrm{p}=0.05)$, this implies that the data deviates from a normally distribution. Multicollinearity was tested by using Pearson correlation coefficient. The test established that there was absence of collinearity since the Pearson correlation for knowledge creation was less than 0.8 . Correlation analysis was conducted to establish the relationship between age of the firm and organizational 
performance. The study found that there was a weak association, $r=0.02, p=0.782$, between return on asset and age of the firm. Also, the study established that there was a weak relationship, $r=0.102, p=0.164$, between age of the firm and return on equity. Therefore, age of the firm was not significantly correlated with organizational performance. The study sought to establish if there was no significant difference in the mean of the age of the firm across the segments. The study found that there was no significance difference, $F(14,172)=1.243, p=$ 0.249 , in the mean of age of the firm for pure and strategic commercial state owned enterprises in Kenya.

Multiple regression analysis was conducted in order to establish the effect of knowledge creation on organizational performance based on age of the firm as moderating variable. The study conducted a regression analysis to determine if age of the firm significantly moderates the relationship between knowledge management and organizational performance. Table 1 shows the result: Age of the firm was statistically significant, $\beta=0.501$, $\mathrm{t}$ (2.508), $\mathrm{p}=0.013$. The coefficient for interaction between knowledge acquisition and age of the firm was statistically significant, $\beta=0.111, \mathrm{t}(2.47), \mathrm{p}=0.015$. The coefficient for interaction between knowledge creation and age of the firm was statistically significant, $\beta=0.149, \mathrm{t}(4.03), \mathrm{p}=0.000$. The coefficient for interaction between knowledge conversion and age of the firm was statistically significant, $\beta=-0.234, \mathrm{t}(-4.178), \mathrm{p}=0.000$. The coefficient for interaction between knowledge sharing and age of the firm was statistically insignificant, $\beta=$ $0.082, \mathrm{t}(-1.843), \mathrm{p}=0.067$. The coefficient for interaction between knowledge storing and age of the firm was statistically insignificant, $\beta=-0.051, \mathrm{t}(-1.156), \mathrm{p}=0.249$. This finding suggested that age of the firm moderated the relationship between return on equity and knowledge acquisition, knowledge creation and knowledge conversion.

Table 1: Coefficients for Age of the Firm on Return on Equity

\begin{tabular}{|c|c|c|c|c|c|}
\hline \multirow[t]{2}{*}{ Variables } & \multicolumn{2}{|c|}{$\begin{array}{l}\text { Unstandardized } \\
\text { Coefficients }\end{array}$} & \multirow{2}{*}{$\begin{array}{l}\text { Standardized } \\
\text { Coefficients } \\
\text { Beta }\end{array}$} & \multirow[t]{2}{*}{$\mathbf{t}$} & \multirow[t]{2}{*}{ Sig. } \\
\hline & & Std. Error & & & \\
\hline (Constant) & -27.545 & 9.383 & & -2.936 & .004 \\
\hline Age of the firm & .501 & .200 & 1.071 & 2.508 & .013 \\
\hline $\begin{array}{l}\text { Interaction between Knowledge Acquisition } \\
\text { and Age of the firm }\end{array}$ & .111 & .045 & 1.141 & 2.469 & .015 \\
\hline $\begin{array}{l}\text { Interaction between Knowledge Creation and } \\
\text { Age of the firm }\end{array}$ & .149 & .037 & 1.415 & 4.030 & .000 \\
\hline $\begin{array}{l}\text { Interaction between Knowledge Conversion and } \\
\text { Age of the firm }\end{array}$ & -.234 & .056 & -2.233 & -4.178 & .000 \\
\hline $\begin{array}{l}\text { Interaction between Knowledge Sharing and } \\
\text { Age of the firm }\end{array}$ & -.082 & .045 & -.784 & -1.843 & .067 \\
\hline $\begin{array}{l}\text { Interaction between Knowledge Storing and } \\
\text { Age of the firm }\end{array}$ & -.051 & .044 & -.505 & -1.156 & .249 \\
\hline \multicolumn{6}{|c|}{$\begin{array}{l}\text { The study conducted a regression analysis to determine if the age of the firm significantly moderates the } \\
\text { relationship between knowledge management and organization performance based on return on asset. All the } \\
\text { coefficients of the interactions between age of the firm and knowledge acquisition, knowledge creation, } \\
\text { knowledge conversion, knowledge sharing and knowledge storing were statistically insignificant implying that } \\
\text { the age of the firm does not moderate the relationship between knowledge management and organizational } \\
\text { performance (return on asset) of commercial state owned enterprises in Kenya. Table } 2 \text { outlined the findings. } \\
\text { Table 2: Coefficients for Age of the Firm on Return on Asset }\end{array}$} \\
\hline Variables & $\begin{array}{l}\text { Unstan } \\
\text { Coeffic }\end{array}$ & $\begin{array}{ll}\text { dized } \\
\text { ts }\end{array}$ & $\begin{array}{l}\text { Standardized } \\
\text { Coefficients }\end{array}$ & $\mathbf{T}$ & Sig. \\
\hline & B & Std. Error & Beta & & \\
\hline (Constant) & 0.07 & 3.632 & & 0.019 & 0.985 \\
\hline Age of the firm & -0.007 & 0.077 & -0.045 & $-\overline{0}(093$ & 0.926 \\
\hline $\begin{array}{l}\text { Interaction between Knowledge Acquisition and } \\
\text { Age of the firm }\end{array}$ & 0.002 & 0.017 & 0.063 & 0.119 & 0.905 \\
\hline $\begin{array}{l}\text { Interaction between Knowledge Creation and Age } \\
\text { of the firm }\end{array}$ & 0.012 & 0.014 & 0.324 & 0.812 & 0.418 \\
\hline $\begin{array}{l}\text { Interaction between Knowledge Conversion and } \\
\text { Age of the firm }\end{array}$ & -0.001 & 0.022 & -0.036 & -0.06 & 0.953 \\
\hline $\begin{array}{l}\text { Interaction between Knowledge Sharing and Age } \\
\text { of the firm }\end{array}$ & -0.003 & 0.017 & -0.083 & $\overline{-}-171$ & 0.864 \\
\hline $\begin{array}{l}\text { Interaction between Knowledge Storing and Age } \\
\text { of the firm }\end{array}$ & -0.008 & 0.017 & -0.239 & $\overline{0.481}$ & 0.631 \\
\hline
\end{tabular}

\section{Discussions, Conclusions and Recommendations}

Age of firm moderates the relationship between knowledge management and organizational performance in state 
owned commercial enterprises in Kenya as measured either by ROE or ROA. The length of time that an organization has been in operation was found to significantly moderate the relationship between knowledge management and organizational performance of state owned commercial enterprises in Kenya as determined by either ROE or ROA.

These results are in agreement with the findings of the study by Hui et al (2013) who studied the effect of Organizational innovation and Organizational learning on organizational performance. The study used structural equation modelling (SEM) and moderation analysis to analyse data from 168 manufacturing companies in food sector chosen from Taiwan, Malaysia and China. The results indicated that age allows organizations to develop organizational routines so that they can perform their operations with more efficiency and enhance their performance. However, younger firms struggle with lack of consolidated procedures implying that innovation requires additional consideration and effort from the learning process.

The outcome of this study that age of firm moderates the relationship between knowledge management and organizational performance also support the findings of studies on the effect of firm age on firm performance by Hussein and Hassan (2012), and Steven, Abby, Feng and Shisong (2017). While exploring the role of knowledge management in enhancing organizational performance in 30 selected medium and large size organizations from public sector organizations, private sector organizations and non-governmental organizations in Cairo, Egypt. Findings indicated a substantial relationship between knowledge management elements and performance improvement measures such as decision-making of the firm. Steven et al (2017) studied 204 China-based Chinese firms based to evaluate how companies' dynamic know-hows result in competitive advantage and influence on firm performance. The study results showed that technological innovation is a critical moderating factor between dynamic capabilities and firm performance.

The study established that age of the firm did not moderate the relationship between knowledge management and organization performance based on return on assets. The results further showed that age of the firm significantly moderated the relationship between knowledge management and organization performance based on return on equity. Specifically, age of the firm moderated the relationship between return on equity, and knowledge acquisition, knowledge creation and knowledge conversion.

The study results showed that Age of firm moderates the relationship between knowledge management and organizational performance in state owned commercial enterprises in Kenya as measured either by Return on Equity. Organizations of all ages need to have in place properly designed, robust knowledge management systems to provide staff flexibility and reduce design time and organizational costs. This must also be supported by developing a culture that embraces learning and sharing knowledge time and again.

\section{Reference}

Ajzen, \& Fishbein, M. (1975). Beliefs, attitude, intention and behaviour: An introduction to Theory and research. Boston: Addison-Wesley Publishing Company Reading.

Ajzen, I. (1991). The Theory of Planned Behaviour. Organisational Behaviour and Human Decision Processes, 50, 319-349.

Ajzen, I., \& Fishbein, M. (1977). Attitudinal and Normative Variables as Predictors of Specific Behaviour. Journal of Personality and Social Psychology, 27(1), 41-57.

Barney, J. B. (1995). Looking inside for competitive advantage. Academy of Management, 49-61.

Conner, K., \& Prahalad, C. (1996). A resource based theory of the firm: Knowledge versus Opportunism. Organisation Science, 7(5), 477-501.

Davenport, T. H. (1994). Saving its Soul: Human-Centred Information Management, Harvard Business Review, Mar-Apr. 1994, pp. 119-131.

Government of Kenya. (2013b). Executive Report on Parastatal Reforms in Kenya. Nairobi: Government of Kenya.

Harlow, H. (2008), "The effect of tacit knowledge on firm performance", Journal of Knowledge Management, 12(1): 148-163.

Kalling, T. (2003). Knowledge management and the occasional links with performance. Journal of knowledge Management, 7(3), 67-81.

Letonja, M. \& Duh, M. (2016). Knowledge transfer in family businesses and its effects on the Innovativeness of the next family generation; Knowledge Management \& Research Practice 14: 213-224. doi:10.1057/kmrp.2015.25

Lee, K.C., Lee, S. \& Kang, I.W. (2005). “KMPI: measuring knowledge management performance”, Information \& Management, 42(3): 469-482.

More, E., Carroll, S., \& Foss, K. (2009). Knowledge Management and Performing Arts Industry. Asia-Pacific Journal of Business Administration, 1(1), 40-53.

Ruchi, P., Salma, A., \& Roma, M. (2016). Knowledge Management and Organizational Performance; A case Study in the Context of Indian Software Companies. The IUP Journal of Knowledge Management, Vol 14, 
No.4, 53-78.

Sher, P. J., \& Lee, V. C. (2004). Information technology as a facilitator for enhancing dynamic capabilities through knowledge management. Information \& Management, 41 (8), 933-945.

Singh, S., Chan, Y., \& Mckeen, J. (2006.). Knowledge management capability and Organizational performance: A Theoretical foundation. OLKC 2006 Conference at the University of Warwick. Coventry.

Vera, D., \& Crossan, M. (2003). Organizational learning and knowledge management: towards an integrative framework. Oxford, Uk: Blackwell Publishing.

World Bank, (2001). Working on administrative and civil service reform. [Online]: http://www1.worldbank.org/prem/acr/ad.html. Accessed 25 June 2017.

Wenger, E. C., \& Snyder, W. M. (1999). Communities of practice: The organizational frontier. Harvard Business Review, 78(1), 139-145.

Yamane, T. (1967). Elementary sampling theory. USA: Prentice-Hall, University of Michigan.

Zaied, H. A., Hussein, S. G., \& Hassan, M. M. (2012). The Role of Knowledge Management in enhancing Organizational Performance: International Engineering and Electronic Business, Vol 4, Issue 5, 27. 